MEDICAL PRACTICE

\title{
The London hospitals scene
}

\author{
SIR FRANCIS AVERY JONES
}

British Medical fournal, 1976, 2, 1046-1049

Many London hospitals are facing a serious crisis both in loss of staff morale and financial stringency. Four interwoven factors are causing the mounting pressures: (a) the Ministerial cash limit; $(b)$ the "standstill" following the recommendations of the Resource Allocation Working Party (RAWP) ${ }^{1}$; $(c)$ national bed norms; and $(d)$ rationalisation. Month after month the London hospitals are becoming increasingly overspent in relation to their cash limit for 31 March 1977. It is a situation that seems to be selectively hitting mainly those hospitals serving poorer districts -hospitals that have few or no reserves for trying to meet the "overspending." The inverted commas are included to indicate that much if not all of the overspending is not due to extravagance or incompetence but to factors over which the hospitals have no control.

\section{The cash limit}

For the first time hospitals have been given a strict cash limit which must not be exceeded by 31 March 1977 . Any deficit will be the first charge on the 1977-8 budget. The allocation includes a sum to cover the expected extra costs due to inflation and pay awards. It is now clear that this sum is proving insufficient and there may be a deficit of several hundred thousand pounds for each district. The "overspending" that each district will be showing must be corrected by the end of the year. The Secretary of State said only recently on the radio that hospitals were protected against inflation. This may have been terminologically correct, but it was a most unfortunate half-truth, and to cope with this deficit a great many posts are no longer being filled as they fall vacant, and the whole service is being weakened in a

Central Middlesex Hospital, London NW10

SIR FRANCIS AVERY JONES, MD, FRCP, consulting physician random and unplanned manner. Inflation should now have been down to $10 \%$ and in single figures within the year, but the target has slipped badly. Furthermore, the full cost of the junior doctors' pay award has to be found within the previously fixed cash limit. The rest of the country has continued to have a buffer with their usual annual incremental growth allocation. For London there is no such buffer, as this allocation was stopped by Mrs Barbara Castle earlier in the year.

\section{The London "standstill"}

Since 1 April 1976 both London and the Mersey region have been without their annual incremental growth allowance so badly needed for rationalising their services. Money thus saved was not handed back to the Exchequer but distributed between other regions on the basis of calculations made by the RAWP, who have adopted a mathematical approach to resource allocation. From the knowledge that the financial allocation to different regions of the country varied by almost $25 \%$ relative to the population, it has been assumed that some regions are deprived and others overfunded. The working party was set up with the admirable objective of determining the cost of the need that exists and for which a proper share of the national cake should be provided.

In its interim report it "weighted" the population in relation to those sections that might be expected to provide a greater claim on the Health Service, particularly the young and the elderly, and then calculated a notional population for each region. This was used instead of the crude population as the basis for the financial allocation. The working party deliberately did not take into account the number of beds in hospitals in these calculations because it thought that supply can create demand and lack of supply can conceal demand and therefore the number of beds was not in itself a true indidation of need. On the basis of these calculations the RAWP made certain radical proposals concerning the allocations for 1976-7, the objective being to swing down higher allocations and increase the lower ones. In February 1976 a political decision was taken by Mrs Castle to put a standstill on growth in the London 
regions and Merseyside. They lost their expected $2 \%$ of incremental growth money, and the "deprived" areas like East Anglia, Trent, and Wessex were given incremental allocations in the region of $4 \%$ (more in the case of Trent).

The standstill on London and Mersey has imposed a tremendous strain on finances and has created an almost impossible climate for the much needed rationalisation. Under Mr Richard Crossman and then under Sir Keith Joseph there had been differential incremental growth allowances to different parts of the country - a very sensible arrangement. The sudden change in time scale seems to have been a serious error. It has created enormous difficulties in London, and there seems to be considerable doubt about the ability of the more favoured regions to spend their extra allocation quickly and effectively within the year.

\section{RAWP'S CALCULATIONS}

The mathematical formula used in these calculations is given in the RAWP report and is set out in fig 1 . The obvious criticism that there was no objective indication of morbidity has been corrected in the final report, which built in a correction for mortality that varies quite considerably around the country. The highest standardised mortality ratios are found in the Mersey (110), North-western (109), and Northern (107) regions and the lowest in Essex and Oxford (91) and East Anglia (92). The various direct indices of morbidity proved to be inadequate, and the working party thought that the mortality ratios might serve as a suitable index. In addition to these new adjustments it also built in a service increment for teaching (SIFT) in relation to medical education. The remarkable variations in the costs suggest, however, that there may be hidden fallacies. Using the formula for further computer calculations RAWP devised a new pattern of weighted population (fig 2). Now East Anglia can no longer be described as a deprived area, and Oxford has moved across the dividing line and joined those regions which are above the average in cost. Presumably these calculations were made too late to stop the extra allocation for East Anglia.

\section{CITIES}

That this recalculation produced such remarkable changes raises the question whether there may not be other factors that should also be taken into account and which might again alter

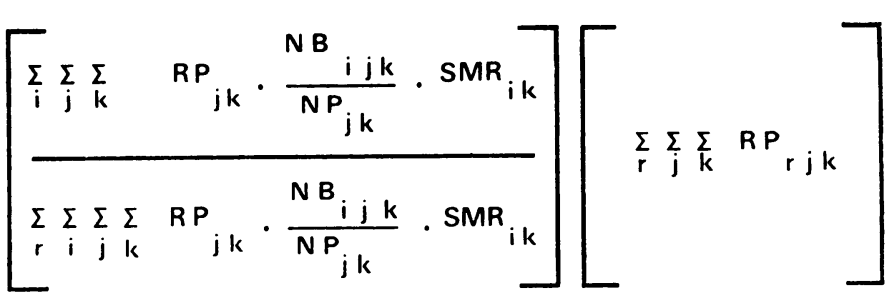

\footnotetext{
Where: $\quad N P=$ national population in year of data on national daily occupied beds $\mathrm{RP}=$ regional population - most recent mid-year estimates

$N B=$ nationa, average number of daily occupied beds

$i=$ condition

$j=$ age group

$k=\operatorname{sex}$

$r=$ region
}

The first bracket relates to the multiplication of the factors to produce expected bed-days for each Region as a fraction of the total, and the second bracket is the national population which is used to convert the fraction to a weighted population.

FIG 1-Algebraic expression for producing populations weighted by age, sex, and condition-specific standardised mortality ratios. Reproduced from the report of the Resource Allocation Working Party ${ }^{1}$ with the permission of the Controller, Her Majesty's Stationary Office.
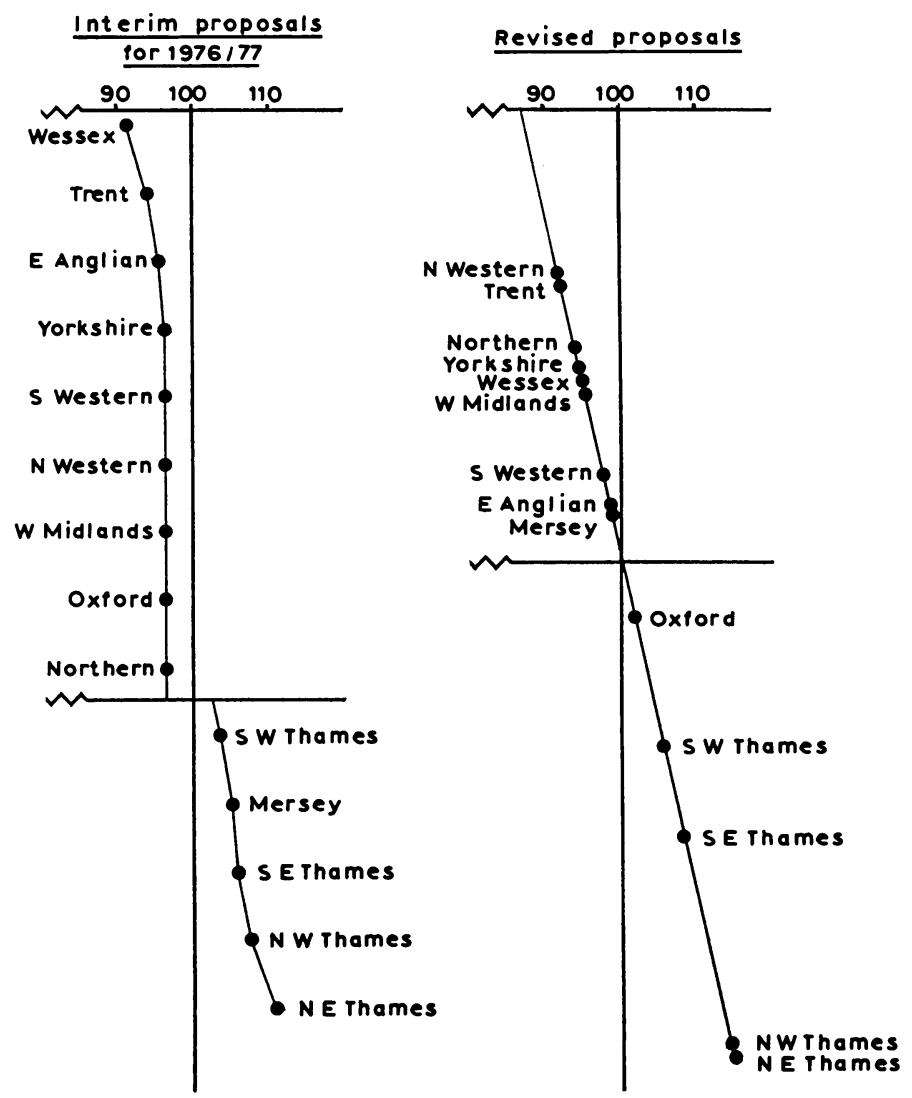

FIG 2-Charts, comparing interim and revised proposals for distributing revenue funds. Reproduced from the report of the Resource Allocation Working Party ${ }^{1}$ with the permission of the Controller, Her Majesty's Stationery Office.

the pattern. One most important factor does not seem to have been considered. In comparing regions the RAWP has not been comparing like with like because of the varying size of the cities within the regions. The larger the city the more expensive all services become. In addition there are the heavy concentrations of urban social deprivation, and it is much more expensive in terms of beds and staff to provide medical and social services for a deprived area than for an affluent one. Alas, instead of building in such a conurbation factor, the formula is to be further complicated by such considerations as agency arrangements, use of community services, inter-regional flow of patients, and condition-specific SMRs, and the weighted population will be further readjusted. Apart from the use of community services none of these new added factors reflect social deprivation. As for community services, there is an obvious fallacy that use relates to supply more closely than to need.

What the working party should do next is to look at the relative costs in the big cities, particularly London, Manchester, Liverpool, and Glasgow. Scottish figures are excluded from the present record, which is a great pity, as there is no mention of the fact that in Scotland the health service allocation is already $25 \%$ above the English allocation, and the number of consultants in proportion to the population is $37 \%$ higher. This may well reflect the serious degree of urban deprivation in the main Scottish cities.

If a conurbation factor were built into the formula to take account of the size of cities and variations in market cost it would probably be found that the expenditure of the former regional hospital boards represented true regional variation without undue extravagance and without undue deprivation in at least most of the regions of the country. At its lower cost East Anglia provides at least as good if not a better health service than is provided in London. It would seem reasonable to approach the calculations made by the RAWP with extreme caution. 


\section{Bed norms}

The next factor in the hospital crisis has been the calculation of bed norms for each specialty in each district. Here again there has been no reference to social deprivation. Within the main cities there are large areas with serious problems of urban deprivation: overcrowding; incomplete domestic services; unemployment; and increased mobility of population, with resulting lack of friends and relations, dreary streets, and traffic pollution. Additional resources and more hospital beds are needed to meet the greater medicosocial needs of such areas. How else can one deal humanely with the acute medical problems of the lonely bedsitter population and the elderly whose children have left the city ? The long-term solution is clearly to improve the social environment. In the short-term there is a continuing need for meeting the greater claims on Health Service resources.

\section{BRENT AND HARROW}

My own experience over many years relates particularly to Brent (Willesden, Kilburn, Harlesden, Neasden, Wembley) in north-west London. The south-eastern areas of Brent are particularly deprived, with overcrowding reaching $70 \%$ above the accepted Greater London Council levels of 1.5 persons per room. As a member of Brent and Harrow Area Health Authority I see all the contrasting figures between Brent and Harrow (see table). Harrow has far better housing, pleasing streets and gardens, and, I suspect, more neighbourliness-a community quality that seems to increase with the distance from the centre of the city, where anonymity is the rule. The mathematical formula for bed allocations, with which we are now faced, allocates exactly the same proportion of beds to Brent as it does to Harrow, and the same principle will be operating between Hampstead and Camden, Dulwich and Southwark, Ealing and Acton.

Ranking order of social factors in Brent and Harrow

\begin{tabular}{|c|c|c|c|c|}
\hline & \multicolumn{2}{|c|}{ Brent } & \multicolumn{2}{|c|}{ Harrow } \\
\hline & $\begin{array}{l}\text { Absolute } \\
\text { values }\end{array}$ & $\begin{array}{c}\text { Ranking } \\
\text { order* }\end{array}$ & $\begin{array}{l}\text { Absolute } \\
\text { values }\end{array}$ & $\begin{array}{c}\text { Ranking } \\
\text { order* }\end{array}$ \\
\hline $\begin{array}{l}\text { Population } \\
\% \text { Of births to "New } \\
\text { Commonwealth" mothers }\end{array}$ & $\begin{array}{c}203210 \\
34 \cdot 5\end{array}$ & 1 & $\begin{array}{l}209400 \\
12 \cdot 5\end{array}$ & 7 \\
\hline $\begin{array}{l}\text { No of residents with both parents } \\
\text { born in New Commonwealth }\end{array}$ & 47865 & 1 & 8022 & 8 \\
\hline $\begin{array}{l}\text { No of illegitimate live births: } \\
\text { Mother under } 20 \\
\text { Mother over } 20\end{array}$ & $\begin{array}{l}206 \\
430\end{array}$ & 1 & $\begin{array}{l}40 \\
98\end{array}$ & $\begin{array}{l}9 \\
9\end{array}$ \\
\hline $\begin{array}{l}\text { No of legitimate live births } \\
(\text { para } \geqslant 6)\end{array}$ & 70 & 1 & 19 & 9 \\
\hline $\begin{array}{l}\text { No of legal abortions } \\
\text { Deaths: }\end{array}$ & 1424 & & 566 & \\
\hline $\begin{array}{l}\text { Adjusted rate :national crude rate } \\
\text { Infants } / 1000 \text { live births } \\
\text { Perinatal mortality } \\
\% \text { Of unsatisfactory school } \\
\text { medicals }\end{array}$ & $\begin{array}{l}0.94 \\
16 \\
1.45\end{array}$ & $\begin{array}{l}5 \\
5 \cdot 5 \\
1 \cdot 5 \\
2\end{array}$ & $\begin{array}{l}0.86 \\
11 \\
0 \cdot 01\end{array}$ & $\begin{array}{r}8 \cdot 5 \\
8 \\
9 \\
9\end{array}$ \\
\hline $\begin{array}{l}\text { No of children coming into care } \\
\text { year ending } 31 \text { March } 1974\end{array}$ & 563 & 4 & 129 & 9 \\
\hline$\%$ Of children needing treatment & $57 \cdot 5$ & 3 & $39 \cdot 1$ & 8 \\
\hline $\begin{array}{l}\% \text { Of households with exclusive } \\
\text { use amenities (1971) }\end{array}$ & $73 \cdot 0$ & 4 & $92 \cdot 9$ & 8 \\
\hline
\end{tabular}

*Taken from Greater London Council statistics (1973). Figures relate to ranking order between the boroughs in North-west Thames Regional Health Authority.

If the full recommendations are accepted, Brent will have to reduce the number of beds for acute medicine and surgery by 310 , from 881 to 571 , and at the same time organise 115 extra beds for geriatric and psychiatric long-stay care-all within the next few months. Patients in acute medical and surgical beds will just have to be returned too soon to their single rooms, and I cannot envisage there being any extra help from the already hard-pressed social services.

The additional health problems of Brent over and above those of Harrow are indeed immense, as can be appreciated from the table. Brent has the highest incidence of tuberculosis of anywhere in London, but there is no allowance for the heavy additional expense of prescribing antitubercular drugs. Surely RAWP should have looked at the special needs of the zones of urban deprivation within our cities. If their computer runs out of figures, let them take a drive 10 miles up the Harrow Road from Paddington to Harrow on the Hill and just make an estimate.

But perhaps after all Brent has been overbedded and overmanned, and my blinkers should be removed. Perhaps patients should be discharged to their single rooms before they have the strength to look after themselves and perhaps the voluntary services should fill the gap. My personal belief, however, is that the sums are wrong-wildly wrong-and that the Secretary of State will have to take some very urgent evasive action, bearing in mind that, like giant tankers, the NHS is very slow to respond to a change of course and speed. Having worked in Brent for 35 years and knowing the district so well, I am certain the sums are wrong.

Already the acute wards have a preponderance of elderly patients, and, indeed, five out of six patients aged over 65 are admitted to acute wards and not to the geriatric service. This is the age group which will suffer particularly from the dramatic reduction in beds for the acute services. Unhappily, because admission will become so difficult for them some will lose their one chance of restoring their function, which might be achieved within the hospital and with all its supporting services. We shall need many of the extra geriatric beds merely to deal with the problem created by the restriction on acute admissions.

\section{DEPRIVING AREAS THAT CAN LEAST AFFORD IT}

Patients are people who come from good, indifferent, or bad environments, with varying needs to get them over their illness. Patients are not statistics, and bed allocation must be related to the background social factors. It is extraordinary that this simple message has again to be restated. The circumstances in the London boroughs of Hackney, Hammersmith, Haringey, Islington, Kensington and Chelsea, Lambeth, Newham, Southwark, Tower Hamlets, Wandsworth, and Westminster have been clearly documented by Holtermann ${ }^{2}$ in her study of urban deprivation. When she imposed a standstill on London and Mersey surely Mrs Castle did not intend that this financial blizzard should hit quite so selectively those parts of London that could least afford it. Decision-taking by the heavily stratified administration being so slow, the full destructive force of this "hurricane Barbara" will persist until 1 April 1977 unless the Secretary of State intervenes. People like myself who have watched the whole development of the NHS since 1948, and who have tried to contribute in full measure, find the present scene depressing beyond words. It is an absolute tragedy because the London health services were splendidly poised for their first real round of rationalisation.

\section{Rationalisation}

If its acute services are rationalised the NHS has a very real chance of progressing providing, in some areas possibly. as much as a $20 \%$ increase in efficiency and thereby making substantial contributions towards helping the national economy. The NHS has already achieved almost a $100 \%$ increase in efficiency since 1948 by almost doubling the number of inpatients with considerably fewer beds. By now every district has prepared plans for concentrating acute resources and overcoming the existing bottlenecks. In line with this there have been plans for increasing the number of long-stay patients and for reducing the load on hospitals by building up primary health care services. Change, however desirable, is always expensive and traumatic to local communities, trade unions, and hospital morale. Unfortunately the political decisions in relation to London, with the standstill and bed norms, have effectively clobbered the London hospitals, which will make it very difficult to achieve an appropriate and orderly rationalisation. 
Politicians, and indeed people in other parts of the country, like to believe that the higher cost of the London health services is due to extravagance, plus an unfair share of special resources such as teaching hospitals and centres of excellence and a corresponding increase in the proportion of junior staff. Certainly, as the capital city, London has attracted a generous share of such centres, and there is a case for some redistribution, which indeed has already started. But the extra cost is not due primarily to higher standards and more centres of excellence but to conurbation factors. Because of its size and magnetic attraction London, like all other big cities, is more expensive, and it is unlikely that the additional cost of hospital services in London is adequately reflected in the London weighting; indeed, this is acknowledged by the RAWP. London has more than its fair share of old, decrepit, inefficient Victorian hospitals, many of which still await refitting. Few have been rebuilt. There is plenty of scope for reducing their costs, but to do so is expensive. The higher cost of London is not due to extravagance: it is due to extra need from conurbation factors.

\section{EAST ANGLIA $v$ LONDON}

Low costs may indicate less need or more efficiency, or both. Here again politicians and the RAWP have misinterpreted some regional figures. There are parts of the country, and East Anglia is a particularly good example, where low cost is related to an efficient service and less need. The East Anglian health services are splendidly organised but, like everywhere else, still need much modernisation. Almost every index of health is consistently better in East Anglia than in London, some to a quite extraordinary degree, especially cardiovascular disease. The proportionate demand on the accident and casualty services is about half the load of London. No doubt the doctor and the patient who are miles from Norwich or Cambridge may deal with the cuts and sprains, whereas in London the patient expects to be sent to the nearby big hospital. With comparable waiting lists in East Anglia there are proportionately only half the number of new outpatient attendances as there are in London NW10 (Willesden and Park Royal). Perhaps the East Anglian general practitioners are more selective in whom they send. Perhaps these practitioners are self-selected for their ability to cope on their own. In East Anglia social deprivation is far below the London level. In East Anglia there is good neighbourliness; in London there is anonymity. East Anglia has the worst weather, with the bitingly cold north-easterly wind in the winter. Nevertheless, the incidence of respiratory diseases is much lower than in London. In spite of its lower cost East Anglia, too, has its centres of excellence, and the orthopaedic work at Norwich has for many years attracted visitors from overseas. It was here that the technique of total hip replacement was first evolved. Cambridge, too, has been responsible for much medical progress.

\section{MORALE}

Why did the RAWP fail so abysmally in their initial comparative estimate of the needs of East Anglia? There is no mystery about this. The working party consisted of medical and lay administrators, statisticians, epidemiologists, treasurers, works officers, but not a single practising general practitioner or consultant. One would have thought that the politicians would have appreciated some clinical perspective in making such an important review. The error in omitting all reference to special needs for social deprivation will become acute when the regions are translating allocations to districts. The guidelines so far produced by the RAWP are dangerously inadequate.

The mathematical approach should be abandoned, and in its place there should be small review parties such as those that have proved so successful in the past. Such working parties would have a reasonable opportunity to evaluate social deprivation factors and the quality of primary care which makes such a difference to the work of a district general hospital. Once allocation figures and reality begin to converge there will be a chance for morale to start its long road to recovery.

\section{References}

${ }^{1}$ Department of Health and Social Security, Sharing Resources for Health in England. London, HMSO, 1976.

2 Holtermann, S, Social Trends, No 6. London, HMSO, 1975.

\section{Where Shall Fohn Go?}

\section{Sweden}

\section{DOUGLAS MACLEAN}

British Medical fournal, 1976, 2, 1049-1051

If you feel like a change, a struggle with ample rewards in the end, then Sweden could be the place to come. If you happen to be an anaesthetist the toil is considerably reduced, as there is no compulsory language examination. This is the one almighty barrier, but, for those who feel like pitching their neurones against something completely different, come to Sweden. The

Stenbocksgatan 15, Lagenhet 18, Malmo, Sweden DOUGLAS MACLEAN, MB, MRCOG, registrar language takes time to learn, a lot of effort, but in the long run is a satisfying and enriching experience.

I came to Sweden as a so-called qualified obstetrician and gynaecologist-that is, with the MRCOG. They fully recognise our degrees and will readily load us with much responsibility. The first six months, however, must be conducted as a provtjänstgöring (trial job as house officer). After this period the chief will send a report to the Socialstyrelsen for foreign doctors, and, assuming this is satisfactory, you can then take off for a higher plane and salary. An underläkares (houseman's) salary is, however, not to be sniffed at, and in fact more than adequate for ordinary activities. All this applies to those who wish to come and work more or less permanently, especially those who are not anaesthetists. Short-term locums are a different matter and 